\title{
ESTADO E EDUCAÇÃO NO CONSTRUTIVISMO INSTITUCIONAL DE ANÍSIO TEIXEIRA
}

Rafael Valladão Rocha*

Resumo: O pensamento político-pedagógico e a obra educacional de Anísio Teixeira podem ser caracterizados por sua imaginação institucional e seu incentivo ao experimentalismo pedagógico. Pretendemos explicitar neste trabalho o conteúdo propositivo e explicativo da obra anisiana, destacando sua concepção de estruturas institucionais como artefato maleável e suscetível de reorganização estratégica, o que se fará a partir das noções de Estado e Educação. Por fim, oferecemos argumentação no sentido de retomar as ideias construtivistas institucionais de Anísio Teixeira como referencial teórico para políticas educacionais inovadoras e padrões superiores de administração pública.

Palavras-chave: Instituições; Estruturas; Educação; Política educacional.

\section{STATE AND EDUCATION IN THE INSTITUTIONAL CONSTRUCTIVISM OF ANÍSIO TEIXEIRA}

\begin{abstract}
Anísio Teixeira's political-pedagogical thinking and educational work can be characterized by his institutional imagination and his encouragement of pedagogical experimentalism. We intend to explain in this work the propositional and explanatory content of the Anisian work, highlighting its conception of institutional structures as a malleable artifact and susceptible to strategic reorganization, which will be done from the notions of State and Education. Finally, we offer an argument in the sense of resuming the institutional constructivist ideas of Anísio Teixeira as a theoretical framework for innovative educational policies and higher standards of public administration.
\end{abstract}

Keywords: Institutions; Structures; Education; Educational policy.

\section{ESTADO Y EDUCACIÓN EN EL CONSTRUCTIVISMO INSTITUCIONAL DE ANÍSIO TEIXEIRA}

Resumen: El pensamiento político-pedagógico y el trabajo educativo de Anísio Teixeira se caracterizan por su imaginación institucional y su impulso al experimentalismo pedagógico. Pretendemos explicar en este trabajo el contenido proposicional y explicativo de la obra anisiana, destacando su concepción de las estructuras institucionales como un artefacto maleable y susceptible de reorganización estratégica, que se hará desde las nociones de Estado y Educación. Finalmente, ofrecemos un argumento en el sentido de retomar las ideas constructivistas institucionales de Anísio Teixeira como marco teórico para políticas educativas innovadoras y estándares superiores de administración pública.

\footnotetext{
* Graduado e licenciado em Ciências Sociais e mestrando em Ciência Política pela Universidade Federal Fluminense, Brasil. ORCID: https://orcid.org/0000-0003-4819-6746. Contato: rafaelvalladao@id.uff.br
} 
Palabras clave: Instituciones; Estructuras; Educación; Política educativa.

\section{Introdução}

Anísio Teixeira é um dos mais eminentes pensadores da Educação na galeria intelectual brasileira. A literatura especializada sobre Anísio Teixeira é vasta e diversificada. Isso se deve, em parte, à complexidade particular da obra teórica e prática do pedagogo, que envolve os mais variados temas - dos métodos e processos pedagógicos à engenharia e arquitetura escolares, do estatuto epistemológico da ciência experimental à educação de jovens e adultos, da qualificação técnica do professorado às políticas de financiamento da escola pública etc. $\mathrm{O}$ volumoso estado da arte em torno de Anísio também se explica pela influência exercida por ele sobre as modernas políticas educacionais de extensão do direito social à educação pública, gratuita e de qualidade.

Entretanto, faltam à literatura corrente mais análises acuradas de uma qualidade característica do pensamento e da prática do mestre de Caetité, qual seja, sua imaginação institucional articulada ao experimentalismo pedagógico. Esses elementos nos permitem classificar Anísio Teixeira como um construtivista institucional - categoria que será adiante explicada. Convém definir brevemente o que significam esses dois termos-chave. Chama-se de imaginação institucional a capacidade de análise dos arranjos institucionais vigentes seguida da prospecção de possibilidades de reorganização das instituições, operando em seu interior de modo a dinamizá-las. Com a expressão experimentalismo pedagógico fazemos referência à disposição de implementar medidas incrementais de aprimoramento das práticas e das instituições educacionais, em regime de verificação permanente dos resultados obtidos. Ora, não é possível conceber projetos de experimentalismo pedagógico sem imaginar sob que condições institucionais será operacionaliza a experimentação - razão pela qual ocorre a vinculação entre imaginar e experimentar. As ideias institucionais de Anísio Teixeira, na medida em que propõem arranjos institucionais alternativos para a experimentação de novos paradigmas educacionais, perfazem um modelo de construtivismo institucional.

É notável que a obra prática e teórica de Anísio Teixeira tenha se construído em momento histórico de vertiginosas transformações estruturais do país, em meados do século XX, quando o Brasil iniciava sua revolução industrial e dava os primeiros passos em direção à modernização produtiva e técnico-científica. O paradigma educacional de Anísio Teixeira vinculou-se ao processo industrial e modernizante do país, consolidando o educador como fonte intelectual de transformações no campo educacional/profissional. Tão auspiciosa 
associação entre educação para a civilização moderna e modernização efetiva das estruturas produtivas só foi possível em virtude do caráter experimentalista do pensamento e da obra de Anísio Teixeira, mas também do perfil intelectual do autor. Segundo Teixeira e Medeiros, “o intelectual construtivista não repousa por trás dos textos e das rotinas acadêmicas. Ele ou ela atuam para testar experimentalmente a validade de suas ideias."

Pretendemos explorar brevemente, nos estreitos limites deste artigo, o conteúdo propositivo da obra anisiana, marcada por imaginação institucional e experimentalismo pedagógico, com potencial de informar iniciativas de reorganização estrutural da combalida educação brasileira. Nesse sentido, será pertinente investigar a significação atribuída por Anísio a palavras-chave como Educação e Estado. Sua concepção de educação escolar se articula às possibilidades transformadoras da ação política conduzida pelo Estado, com o objetivo estratégico de reorientar as práticas pedagógicas no sentido de constituir e consolidar um autêntico regime democrático entre nós.

\section{Construtivismo institucional, o primado da inovação institucional}

O processo de constituição e consolidação do Estado nacional brasileiro, em seus aspectos econômicos, socioculturais e políticos, é preocupação constante dos pensadores alinhados a essa corrente intelectual. Seus primeiros representantes se concentraram em torno do problema da unidade institucional da nação, propondo soluções para aprimorar a eficácia da engenharia política e econômica, em momento histórico marcado pela rejeição do ideário democrático-liberal. Oliveira Viana, Alberto Torres e Francisco Campos se situam no primeiro momento do construtivismo institucional, marcada pela proposição de uma arquitetura política autoritária cuja função estratégica seria encaminhar um projeto emancipatório do país, promovendo o desenvolvimento a partir de um núcleo localizado no Estado. Em fins da primeira metade do século passado, a questão nacional se traduzia na reorganização das estruturas produtivas do Brasil e na garantia das liberdades civis anteriormente às liberdades políticas ${ }^{2}$.

Francisco Campos, ideólogo do getulismo, expôs em seu livro O Estado Nacional um plano de iniciativas substitutivas do liberalismo vigente, visando contribuir não para

\footnotetext{
1 TEIXEIRA, Carlos Sávio Gomes; MEDEIROS, Tiago. O Construtivismo Institucional e a Democracia Brasileira. Revista de Ciências do Estado, Belo Horizonte, v. 6, nº 2, p. 01-20, 2021.

2 TEIXEIRA, Carlos Sávio Gomes. Modos de explicar o Brasil: o estruturalismo sociológico de Florestan Fernandes e o construtivismo institucional de Mangabeira Unger. Sinais Sociais, Rio de Janeiro, v. 10 n $^{\circ} 28$, p. 55-79, mai.-ago. 2015.
} 
reformas isoladas e pontuais, mas para uma ampla reestruturação institucional do Brasil. Se “as formas parlamentares da vida política são, hoje, resíduos destituídos de qualquer


econômicas de modo a produzir as transformações almejadas. A proposta autoritária de Campos, inspirada no fascismo europeu, adquiriu forma no Estado getulista, sobretudo em sua fase ditatorial iniciada em 1937 e apenas destruída após o fim da Segunda Guerra Mundial. Na área educacional, Campos comandou o recém-criado Ministério da Educação e Saúde, tendo promovido reformas inovadoras do ensino secundário e dos cursos universitários e ampliado a ingerência da União sobre as redes municipais, estaduais e privadas de ensino, valorizando o vínculo escola-trabalho mediante o encaminhamento de alunos a cursos superiores ou a ofícios profissionais. As reformas de Campos encetaram reestruturação institucional marcada pelo signo da modernização ${ }^{4}$. Nesse momento, a imaginação institucional passa a ser recurso intelectual de inestimável valia para informar políticas inovadoras e ações reorganizadoras do escopo e do alcance das organizações públicas educacionais.

A atuação intelectual e ministerial de Francisco Campos se orientou no sentido de propor e implementar mudanças objetivas capazes de realizar os objetivos colocados no largo horizonte de expectativas de um país em vias de se desenvolver amplamente. É característico do construtivista institucional a concepção de artificialidade das estruturas políticas, econômicas e sociais. Para esses intelectuais, a análise dos desafios estruturais e a prospecção das possibilidades de superação conduz à formulação de programas de enfrentamento dos problemas e de aproveitamento da potência reprimida ou estagnada do país. A imaginação e a efetivação de políticas nesse sentido transformador mostraram-se imprescindíveis para o Brasil operar a evolução de país agroexportador a nação industrial em desenvolvimento, entre as décadas de 1930 e 1960. Vivia-se momento de prodigiosa modernização do país, e, nesse contexto, a educação teria de ser transformada para se compatibilizar com as exigências técnicas e socioculturais da revolução produtiva. Como diz Romanelli5, "a intensificação do capitalismo industrial no Brasil, que a Revolução de 30

\footnotetext{
${ }^{3}$ CAMPOS, Francisco. O Estado Nacional: sua estrutura, seu conteúdo ideológico. Brasília, Senado Federal, Conselho Editorial, 2001, 226 p.

${ }^{4}$ DALLABRIDA, Norberto. A reforma Francisco Campos e a modernização nacionalizada do ensino secundário. Educação, v. 32, nº 2, p. 185-191, 2009.

${ }^{5}$ ROMANELLI, Otaíza. História da Educação no Brasil. 8 a edição. Petrópolis, Vozes. 1986, p. 59.
} 
acabou por representar, determinou consequentemente o aparecimento de novas necessidades educacionais."

Comentando a Constituição de 1937, Francisco Campos afirma que a carta "atribui ao Estado, como seu primeiro dever em matéria educativa, o ensino pré-vocacional e profissional destinado às classes menos favorecidas", com o fim de conduzir a infância e a juventude, até então desassistidas e ensombradas pela ignorância, "ao cumprimento de suas

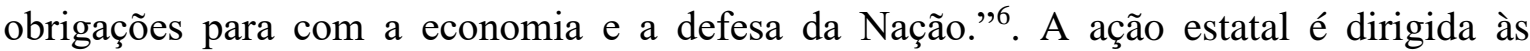
populações não-escolarizadas com o objetivo de integrá-las à sociedade letrada, e assim acelerar o ritmo de inserção do Brasil na pujante civilização técnico-científica do capitalismo. Note-se que o autoritário Campos, ideólogo do Estado Novo, não impôs à educação nenhum arranjo totalitário de corte fascista. Antes, sua obra educacional nos legou uma ampliação do escopo de ação estatal, além de um senso de unidade nacional traduzido em uma coesa organização institucional.

Nesse cenário histórico de modernização educacional e desenvolvimento gradual das estruturas produtivas do Brasil, encontra-se Anísio Teixeira como proponente de uma educação adaptada às necessidades históricas e econômicas da sociedade brasileira. Sem filiar-se às correntes autoritárias, mas tributário da concepção de escola pública mantida e organizada pelo poder público, Anísio Teixeira, junto a outros intelectuais e pedagogos, subscreve o Manifesto dos Pioneiros da Escola Nova, em 1933, em que defende a escola pública, laica e gratuita, onde meninos e meninas receberiam um ensino comum e capaz de habilitar as novas gerações para o desempenho competente de funções profissionais e para o exercício consciente da cidadania.

O caráter liberal-pragmático do pensamento anisiano o indispôs com iniciativas de centralismo autoritário, levando-o a defender uma gestão autônoma da Educação por classes profissionais de educadores, protegidos contra a intromissão deletéria dos governantes de ocasião. É esse aspecto liberal do pensamento de Anísio Teixeira que nos permite situá-lo na vertente democrática do construtivismo institucional, marcada pela defesa de gradual democratização socioeconômica, sem que sejam necessárias crises e rupturas traumáticas da ordem para transformar a realidade.

Diante dos constrangimentos históricos impostos pela guinada desenvolvimentista operada no país, Anísio Teixeira compreendeu ser o momento histórico oportuno para se

\footnotetext{
${ }^{6}$ CAMPOS. O Estado Nacional, p. 67.
} 
efetivarem mudanças estruturais que elevassem as possibilidades de realização material e espiritual da nação. Longe de aceitar passivamente as novidades do tempo como sinais manifestos de um inexorável destino de prosperidade, Anísio se movimentou no sentido de construir instituições capazes de atacar os males derivados da modernização, por um lado, e de aproveitar ao máximo a potencialidade criadora da civilização moderna, por outro lado associando as mudanças na estrutura produtiva às mudanças na educação. A criação das bases educacionais para o progresso da nação é conduzida no interior da ordem social presente, e não por irrupções revolucionárias inconsequentes. Para Anísio, como para outros construtivistas institucionais, a mudança almejada pode se operar de modo endógeno à operação da ordem social, sem recurso necessário à irrupção drástica da ordem presente ${ }^{7}$.

\section{Educação para a civilização moderna}

Anísio Teixeira foi incansável defensor de uma escola pública, gratuita, universal e de qualidade. Escola básica mantida com recursos públicos, administrada pelo Estado, dirigida às crianças e aos adolescentes comuns do povo brasileiro. Em seu discurso pedagógico, encontram-se dois objetivos fundamentais: tornar a educação acessível ao maior número possível de pessoas; sintonizar a escola com as demandas modernas por qualificação técnica e científica da sociedade. Esses objetivos se justificam a partir da constatação do arcaísmo e do dualismo de classe que marcaram historicamente a escola brasileira. Tratavase de responder aos desafios impostos pelas condições objetivas de um sistema escolar inexistente ou claudicante.

Desde os primórdios da colonização, havia no país uma oposição fundamental entre livres e escravizados, distinção de caráter jurídico, sociocultural, econômico e existencial, que reservava a muitos uma vida inteira de servidão e embrutecimento, e distribuía a poucos as benesses da civilização - como educação formal. Após a independência, permaneceu a escola elementar restrita às camadas livres e abonadas da sociedade imperial, ao passo em que o ensino superior servia tão somente para diplomar os novos doutores egressos das elites senhoriais. A proclamação da República trouxe consigo uma série de promessas liberais de universalização de direitos, entre eles, o direito à educação. Embora os primeiros governos republicanos tenham implantado escolas primárias e normais, elas permaneciam em número inferior ao mínimo necessário para atender as populações analfabetas, e as que havia não

\footnotetext{
${ }^{7}$ TEIXEIRA. Modos de explicar o Brasil, cit.
} 
atraíam nem mantinham alunos das classes populares, de modo que persistia entre nós a dicotomia senhor-súdito, convertida em outro dualismo, qual seja, o esclarecido-ignorante. Esta dicotomia teria origens na própria organização social das primeiras décadas do Brasil republicano, quando a economia agroexportadora, em estado inercial, não exigia mais força de trabalho qualificado. ${ }^{8}$

À época não se pensava em educação universal e gratuita. As poucas escolas primárias ofereciam instrução obsoleta, marcada por enciclopedismo estéril sintomático da longeva tradição escolástico-contemplativa dos colégios católicos, e insistiam inutilmente na cartilha de alfabetização e quatro operações matemáticas. Os ofícios manuais eram prematuramente transmitidos às crianças já nos primeiros anos de escolarização, objetivando formar força de trabalho antes mesmo de o indivíduo atingir maturidade cognitiva suficiente para se reconhecer no mundo como ser autônomo. Às escolas secundárias cabia a função de encaminhar o estudante aos concorridos cursos superiores, e, não por acaso, poucos alunos chegavam às séries finais, de maneira que ao filho das classes populares bastavam o beabá grosseiro e os rudimentos de ofício aprendidos na escola primária. Ampliava-se, na escola, o dualismo intolerável fundado na depreciação do trabalho manual e na sobrevalorização da cultura contemplativa. As estruturas sociais, marcadamente desiguais, pareciam se trespassar a instituição escolar.

A educação completa - do primário ao secundário - permanecia um privilégio estamental, tanto mais porque a escola não oferecia um ensino comum de qualidade para os diferentes estratos sociais eventualmente reunidos na mesma sala de aula, mas, antes, reforçava um paradigma escolástico e livresco já conhecido por alunos oriundos das classes superiores. Havia, nesse cenário, dois problemas centrais: o tipo de ensino formatado num padrão ultrapassado de memorização e repetição de conteúdos pouco úteis ou mesmo abstratos e ininteligíveis - o arcaísmo -, e a escola que perpetua a divisão dos alunos em grupos de trabalho manual e grupos de trabalho mental - dualismo. Esse duplo problema entravou, a um só tempo, a inserção intelectual e social do aluno na alvorada técnicocientífica que se anunciava, e a modernização do trabalho exigida pelo capitalismo industrial, posto que fosse a escola, mais que qualquer outra instituição social, a fonte primordial de recursos humanos para a emergente economia capitalista. No entendimento de Anísio:

Educação é a função natural pela qual a sociedade transmite a sua herança de costumes, hábitos, capacidades e aspirações aos que nela ingressam para a continuarem. A educação escolar é um dos modos por que se exerce tal função.

\footnotetext{
${ }^{8}$ ROMANELLI. História da Educação no Brasil, cit., p. 45.
} 


\begin{abstract}
$\mathrm{Na}$ escola ela se faz dirigida e intencional. Obedece a planos. Gradua-se. Distribuise inteligentemente. Entregues a si mesmos, os homens se educariam, mas sem endereços apropriados, tornando-se todos capazes, aproximadamente das mesmas coisas, e diminuindo assim a riqueza de recursos humanos de que precisa a sociedade para se manter e desenvolver adequadamente. A escola regula a distribuição social. Daí não ser a educação escolar mais do que um esforço para redistribuir os homens pelas diversas ocupações e meios de vida em que se repartem as atividades humanas. Assim entendida, toda educação escolar é profissional. Toda educação visa preparar os homens para alguns dos grandes tipos de ocupação9.
\end{abstract}

Trata-se, portanto, de compreender a escola e o trabalho produtivo como elementos associados na vida social, considerando-os componentes de um conjunto holístico, cada um dotado de especificidades que os distinguem sem, contudo, separá-los. Com o fim de estabelecer uma educação adaptada às necessidades industriais, Anísio defende uma escola pluritécnica e multifacetada. Para desempenhar satisfatoriamente seu papel na promoção do desenvolvimento integral do Brasil, a escola moderna deve assimilar os conhecimentos produzidos pela moderna ciência experimental, e conjugar no mesmo espaço diferentes cursos técnico-profissionais. A modernização escolar atende também a outro propósito, central para o pensamento humanista anisiano: oferecer ao estudante participação no patrimônio científico e cultural da civilização ocidental. É nesse sentido que Anísio defende um ensino feito "pelo trabalho e pela ação, não somente pela palavra e pela exposição, como quando o conhecimento racional era de natureza especulativa e destinado à pura contemplação do mundo". ${ }^{10}$

As velhas escolas primárias e secundárias, baseadas na transmissão de cultura humanista e especulativa, devem ceder espaço a escolas técnicas, que, contudo, não abdicariam do espírito imaginativo e do intelecto que animaram a educação tradicional. Deve-se substituir o dualismo manual-mental, reflexo da divisão de classes, por uma simbiose capaz de reunir no interior da escola as diversas vocações e seus respectivos métodos de ensino. São eloquentes as seguintes palavras de Anísio, sobre as escolas que “devem se articular dentro do mesmo espírito, para uma preparação de técnicos em todos os graus e ramos, destinados a servir a um período da idade humana profundamente científica e de caracterização acentuadamente técnica."11 A noção de "técnica" é definida pelo autor nos termos de um processo racional e objetivo de se fazerem as coisas e de se explicarem os fenômenos. Se a técnica, assim concebida, escapa aos domínios da guilda medieval e domina

\footnotetext{
9 TEIXEIRA, Anísio. Educação para a Democracia. $2^{\text {a }}$ edição. Rio de Janeiro, Editora UFRJ, 1997, p. 43.

${ }^{10}$ TEIXEIRA, Anísio. Educação não é privilégio. $5^{\text {a }}$ edição. Rio de Janeiro, Editora UFRJ, 1994, p. 45.

11 TEIXEIRA. Educação para a Democracia, cit., p. 48.
} 
diversos níveis da vida social, seria necessário adaptar a escola básica ao paradigma técnicocientífico que se anunciava.

Por que essa educação pluritécnica e multifacetada deva ser agenciada prioritariamente pelo Estado, e não pela iniciativa privada, é uma questão respondida em duas etapas. Primeiramente, as desigualdades socioeconômicas condicionam à renda familiar o acesso à educação escolar, de modo que uma instituição pública pode oferecer um serviço gratuito aos que dele precisam e não podem pagar. Outra razão diz respeito à capacidade organizadora e diretiva do poder público, pois a modernização escolar exige uma organização complexa somente executada por mãos de uma administração dotada de recursos humanos e materiais suficientemente qualificados. Ou seja, o Estado, por suas características institucionais próprias, possui maior capacidade de planejar e executar um projeto educacional específico que responda às necessidades profissionais e tecnológicas de um país aspirante ao desenvolvimento. Diga-se, a educação pública ambicionada por Anísio é baseada no espírito do tempo capitalista, tempo em que "todos têm de produzir", em que "técnicas científicas e técnicas industriais sobrepuseram-se aos encantamentos da vida do espírito". ${ }^{12}$

\section{Educação, capitalismo e desigualdade social}

Anísio propôs um novo paradigma de educação, paradigma de escola pluritécnica e multifacetada cujo objetivo precípuo é qualificar profissionalmente alunos com as mais diversas orientações vocacionais, desenvolvendo talentos particulares no escopo amplo da missão social. No novo arranjo institucional proposto, há dois aspectos notáveis. O primeiro é de caráter sociocultural e econômico; o segundo, administrativo. Eles convergem no sentido de promover a racionalização da educação pública e a modernização da sociedade brasileira.

A ênfase do atendimento escolar obrigatório e universal, no discurso anisiano, rendeu ao autor acusações de "socialista", por parte de entidades católicas. Prover às massas uma educação condizente com o espírito técnico-científico da modernidade seria, diziam seus detratores, estimular o materialismo. Porém, se admitirmos que toda expressão de socialismo revolucionário implica na abolição do sistema capitalista, e em sua imediata substituição por uma economia de meios coletivos de produção, então ficará evidente a

\footnotetext{
12 Ibidem, p. 46.
} 
incompatibilidade de Anísio com qualquer fôrma ideológica socialista. Anísio, na verdade, estava comprometido com a "viabilidade do capitalismo ou o remédio e o freio para os

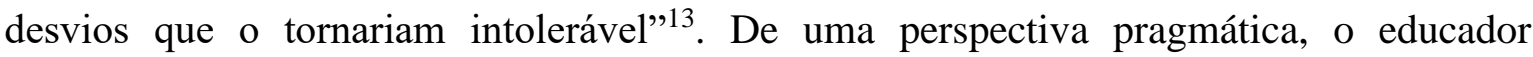
compreendia que a estabilidade de um sistema econômico baseado no trabalho assalariado dependeria da prevenção e contenção dos conflitos que eventualmente surgiriam. Nesse sentido, caberia à escola uma função social decisiva para a ordenação produtiva do Brasil.

Essa função social desempenhada especificamente pela escola seria oferecer ao cidadão comum não somente uma formação escolar qualificada, mas também um senso superior de cidadania ${ }^{14}$. No Brasil, a democracia liberal se instalou primeiramente como regime de sufrágio popular, faltando ao nosso liberalismo democrático um povo cioso de seus direitos, com consciência de sua posição particular na estrutura produtiva. Em sociedade estamental recém-saída da escravidão e apenas vacilantemente introduzida ao capitalismo industrial, era natural que os trabalhadores comuns servissem aos patrões de modo apático e passivo semelhante ao de pessoas escravizadas. Anísio compreendia que a progressão da marcha industrializante conduziria ao acirramento das tensões de classe, o que poderia estimular a desordem e a exploração impune dos trabalhadores. Ora, nas nações em que o capitalismo aportou primeiro, a escola pública precedeu a fábrica. Nesses países, a escola pública se alastrou no interior da sociedade como uma instituição educativa em sentido amplo, pela qual se formaram indivíduos treinados não apenas na técnica para o exercício de um ofício, mas forjados na consciência de seus direitos e deveres, capazes de se organizar autonomamente e resistir à injustiça social de classe quando esta se manifestasse. É o que se depreende das palavras do autor:

\begin{abstract}
A escola pública, comum a todos, não seria assim, o instrumento de benevolência de uma classe dominante, tomada de generosidade ou de medo, mas um direito do povo, sobretudo das classes trabalhadoras, para que, na ordem capitalista, o trabalho (não se trata com efeito de nenhuma doutrina socialista, mas do melhor capitalismo) não se conservasse servil, submetido e degradado, mas igual ao capital na consciência de suas reivindicações e dos seus direitos. (...) A sobrevivência do capitalismo, em grande parte do mundo, não se explica senão por estes dois recursos ou instrumentos de defesa contra a desigualdade excessiva que o capitalismo provocaria e provoca, sempre que faltem ao povo escola pública e sindicato livre ${ }^{15}$.
\end{abstract}

\footnotetext{
13 TEIXEIRA. Educação não é privilégio, cit., p. 81.

14 BALESTRIN, Mariana; SPONCHIADO, Breno Antônio; SUDBRACK, Edite Maria. A contribuição do pensamento de Anísio Teixeira para a formação do cidadão democrático na sociedade brasileira. Revista de Educação Popular, v. 16, nº 2, p. 125-135, 21 nov. 2017.

15 TEIXEIRA. Educação não é privilégio, cit., p. 81.
} 
Ao mencionar o sindicalismo, Anísio considera as duas instituições - sindicatos livres e escolas públicas - importantes para a consolidação da economia capitalista no país, pois compensam retroativamente o atraso civilizatório legado por séculos de escravidão e inércia institucional. Trata-se de acelerar o processo social amplo de implantação do capitalismo entre nós, em vez de abraçar a vocação agroexportadora ou de insuflar uma aventura revolucionária. Essa iniciativa transformadora se faz por meio de instituições vigorosas e engenhadas com elevadas expectativas, e só se concebe por meio de uma imaginação institucional vigorosa e criativa, capaz de reorganizar estruturas sociais sem recurso à implosão revolucionária ou ao imobilismo pusilânime.

A despeito da trajetória errática da economia e da inexperiência democrática no país, Anísio entende ser possível e necessário promover o desenvolvimento integral da nação por meio de uma instituição basilar: a escola pública. O estabelecimento dessa escola pelo Estado, por sua inarredável complexidade, é um processo desdobrado em múltiplas etapas e em diversos níveis de administração. Em sua integralidade, porém, esse processo representa um esforço de modernização racional da Educação no Brasil, contemplando um amplo programa de ações reformadoras das instituições educacionais. À frente da educação institucional, como intelectual e administrador público, Anísio nos legou obra prática de cuja influência sobranceira dificilmente podem escapar as novas gerações de homens de ideias e homens de ação.

\section{Modernização racional da educação pelo Estado}

Como administrador público da Educação, no governo do Distrito Federal, entre 1931 e 1935, e no governo do estado da Bahia, entre 1947 e 1951, Anísio Teixeira promoveu um conjunto de iniciativas reformadoras visando a construção de um arcabouço institucional favorável ao sucesso do empreendimento educacional. Sua gestão trouxe transformações posteriormente replicadas em escala nacional ${ }^{16}{ }^{17}$.

No Rio de Janeiro, Anísio empreendeu uma ampla reforma institucional da Educação. A análise de sua obra inovadora será dividida em dois grupos de iniciativas distintas, porém articuladas num mesmo projeto reformador. São iniciativas de ordem: a) político-administrativa; b) profissional. Em cada um desses grupos enquadram-se ações

\footnotetext{
${ }^{16}$ PAULILLO, André Luiz. As estratégias de administração das políticas públicas de educação na cidade do Rio de Janeiro entre 1922 e 1935. Revista Brasileira de Educação, v. 14, nº 42, 2009.

${ }^{17}$ LIMA, Hermes. Anísio Teixeira: estadista da Educação. Rio de Janeiro, Civilização Brasileira, 1978.
} 
criativas de reorganização institucional, que, em seu conjunto, perfazem um esforço metódico de modernização das estruturas políticas da Educação pública. Essas ações responderam a problemas específicos de a) gestão estratégica e de b) baixa qualidade do recurso humano. Estavam elas animadas por espírito de experimentação, mais tarde materializado na construção de escolas-parque na Bahia.

No campo político-administrativo, suas propostas e realizações visaram satisfazer necessidades intrainstitucionais e interinstitucionais. As primeiras são necessidades de gestão interna dos departamentos e secretarias estatais de prestação dos serviços públicos; as segundas, necessidades mais complexas de relação e integração entre órgãos públicos de diferentes níveis administrativos. Assumindo a Diretoria Geral de Instrução Pública com o objetivo de oferecer à população carioca um serviço educacional qualificado, era necessário, antes disso, certificar-se da capacidade organizativa da própria Diretoria. Anísio implementa, então, uma série de mudanças substanciais na estrutura interna da pasta, visando constituir e consolidar um novo padrão de qualidade administrativa.

O cenário encontrado marcava-se por distribuição irregular de competências, pois as responsabilidades se dividiam confusamente em três subníveis desarticulados, marcado por "despropositada autonomia, cada escola resolvia seus problemas dentro das próprias possibilidades, sem relação com as demais e quase sem controle central" ${ }^{18}$. Havia, também, ausência de ferramentas técnicas e métodos quantitativos para a avaliação da situação geral das escolas e seus estudantes. Anísio propõe, então, a criação de serviços especializados, administrados de maneira coordenada. Do contrário, não seria possível ao administrador público da Educação viabilizar satisfatoriamente seu trabalho:

Só ao Diretor Geral deve caber a totalidade das funções (...), e por isso mesmo tem ele de ser auxiliado por órgãos tão diversos e tão diversos técnicos de ensino. (...) A falta, entretanto, de órgãos qualitativamente especializados, para estudo de condições e execução de planos, levava-o a não preencher inteiramente as suas funções. (...) O exercício simultâneo e indispensável de suas várias incumbências normais quase não lhes era possível, porque lhes faltavam os elementos de apreciação permanente e articulação indispensável à tresdobradura dos aspectos do seu trabalho. ${ }^{19}$

Visando ordenar a administração caótica de então, Anísio obtém, por meio do decreto $n^{\circ} 3763 / 1932$, a criação de serviços especializados no interior da Diretoria de Instrução Pública, com o que organizou um sistema integrado de informações e ações. Esse

\footnotetext{
${ }^{18}$ LIMA. Anísio Teixeira, cit., p. 114.

${ }^{19}$ TEIXEIRA. Educação para a Democracia, cit., p. 135-136.
} 
sistema englobou, além do ensino secundário geral e profissional, áreas tão diversas como matrícula e frequência de estudantes, classificação e promoção de alunos, programas e currículos, obras sociais escolares, educação física e higiênica, música e canto, prédios e patrimônio escolar, estatística e cadastro, contabilidade, publicidade, recursos humanos e arquivo. O pressuposto deste esforço racionalizador da gestão era: a identificação e a resolução de problemas de administração pública não prescindem nunca das ferramentas de registro e seleção de dados, nem dos mecanismos internos de controle e de hierarquia.

O intento de Anísio em edificar um sólido sistema escolar no Distrito Federal rendeu frutos na forma de instituições educacionais, entre elas destacando-se dois institutos - o Instituto de Educação, escola básica (primário e secundário) e superior de magistério, visando formação profissionalizante e técnico-científica dos futuros docentes; o Instituto de Pesquisas Educacionais, órgão de inteligência educacional voltado para "o estudo e elaboração de planos, programas, métodos e processos de educação e ensino e de medidas de rendimento e eficiência, tendo por base investigações sociais e psicológicas" ${ }^{20}$, e, no campo administrativo, voltado para “a organização e coordenação das instituições complementares da escola". ${ }^{21}$

Anísio objetivou imprimir ao conjunto dos grupos e dos serviços um senso de unidade institucional baseado na hierarquização atributiva e na integração operativa. Divisão sistematizada de funções e coordenação competente, duas marcas distintivas da racionalização burocrática do Estado moderno, só se operaram tardiamente no campo educacional brasileiro. Sabedor da tragédia usual de gestões acéfalas, sem liderança nem linha de comando objetivamente definida, Anísio escreveu: "todo o conjunto de medidas destinadas a ajustar o ensino ao indivíduo exige para sua aplicação proveitosa controle centralizado e sistemático".22

A existência de um tal controle centralizado e sistemático, contudo, não implica em instituir um centro decisório onipotente. Não se trata de estabelecer um controle demasiado rigoroso a ponto de sufocar iniciativas meritórias apenas possíveis em cenário de coordenação descentralizada. Devido à sua formação liberal, fundada no pragmatismo de John Dewey ${ }^{23}$, Anísio compreendia que a administração escolar está fundada no elemento

\footnotetext{
${ }^{20}$ Ibidem, p. 158.

${ }^{21}$ Ibidem, p. 158.

22 Ibidem, p. 145.

23 MENDONÇA, Ana Waleska et al. Pragmatismo e desenvolvimentismo no pensamento educacional brasileiro dos anos de 1950/1960. Revista Brasileira de Educação, v. 11, nº 31, 2006.
} 
humano socializado e enraizado em dada comunidade, que, recebendo o auxílio técnico e a orientação superior devida, pode conduzir sua vida educacional com relativa autonomia administrativa. É nesse sentido que identificamos uma segunda ordem de contribuições práticas de Anísio Teixeira para a resolução de problemas político-administrativos, ou seja, a das necessidades interinstitucionais. Essas contribuições estão condensadas em suas propostas para uma organização municipalista da educação básica.

Contra os excessos centralistas ou atomistas, Anísio afirma a necessidade de descentralização administrativa articulada a procedimentos de avaliação e supervisão por parte da União e estados. Seu pensamento reserva papéis distintos e complementares às três instâncias do regime federativo: ao município cabe a escola primária, ao estado a escola secundária e média - incluindo escolas normais -, e finalmente, à União compete manter universidades e cursos superiores, normatizar a profissão docente e fornecer recursos financeiros a municípios e estados necessitados. Anísio também atribui à União o estabelecimento de "exames de Estado" com o objetivo de verificar e avaliar o conhecimento médio dos estudantes. O mesmo modelo de exames se aplicaria ao ensino superior, ajustando-se aos mecanismos de avaliação e classificação da qualidade geral da educação. Ao dividir as responsabilidades, Anísio repercute as ideias de subsidiariedade e cooperação típicas do federalismo em que o Brasil republicano plasmou seu quadro de instituições de governo. $^{24}$

O município adquire importância particular. Uma nova escola pública deve servir à articulação do ensino técnico-científico com as demandas regionais por determinados tipos de trabalho especializado, possibilitando, por exemplo, contato orgânico entre agricultores especializados e uma escola básica de ciências agrícolas e ecologia. Ora, esse contato interinstitucional é tanto mais proveitoso quanto maior for a proximidade da escola em relação aos tipos dominantes de trabalho na região, o que configura a formação de uma municipalidade educacional orientada para o incremento produtivo local. Em época ainda marcada por baixa integração logística entre as várias regiões do continental território brasileiro, a escola anisiana encontrava raízes sólidas na comunidade à sua volta, mais que em circuitos institucionais capazes de reunir as singularidades locais na mesma unidade administrativa.

\footnotetext{
${ }^{24}$ ARAÚJO, Gilda Cardoso de. A relação entre federalismo e municipalização: desafios para a construção do sistema nacional e articulado de educação no Brasil. Educação e Pesquisa, v. 36, nº 1, p. 389-402, 2010.
} 
Quanto à gestão, cada unidade escolar deve ser administrada pelo município em que está situada, de modo a produzir um cenário auspicioso de sinergia escola-cidade ${ }^{25}$. Se "o programa da escola será a própria vida da comunidade, com o seu trabalho, as suas tradições", ${ }^{26}$ então é lógico concluir que a administração escolar, responsável por elaborar e implementar o programa educacional, seja atribuída ao município. É nesse sentido que Anísio propõe um modelo de gestão educacional baseado em conselhos municipais escolares, órgãos locais compostos por representantes autorizados da comunidade e das escolas, com autonomia equiparada à da Câmara de Vereadores, "com poderes reais e não fictícios de gestão autônoma do fundo escolar municipal e direção das escolas locais". ${ }^{27}$

A proposta anisiana de gestão educacional baseada em conselhos municipais se orienta no sentido de abrir caminho à multiplicação de unidades escolares no interior do vasto território nacional. Aproveitando-se da oportunidade propiciada pela distribuição de poderes e prerrogativas instituída pelo regime federativo, Anísio pretende empoderar o único agente político presente em todo o país: o município. Contudo, o municipalismo educacional de Anísio, inspirado nos ideais descentralizadores de Tavares Bastos e Rui Barbosa, está eivado do idealismo utópico criticado por Oliveira Viana em intelectuais liberais ${ }^{28}$. Afinal, não é razoável supor que a educação básica, entregue à administração local de profissionais da educação reunidos em conselho, possa se implementar sem sofrer a ingerência deletéria do mandonismo derivado de nossas tradições oligárquicas. Além disso, a delegação de autoridade a entidades profissionais poderia facilmente conduzir à concentração de poder em núcleos corporativistas infensos a mudanças de ordem institucional, sequestrando o poder decisório em favor de grupos de pressão. Trata-se de uma distorção analítica sintomática do tecnicismo anisiano - que, embora mais inofensivo do que dizem seus detratores, existe de fato.

Apesar das limitações práticas, aproveita-se da tese municipalista o objetivo estratégico de liberar a vitalidade criativa das pessoas comuns que habitam o município. Seguindo-se à crítica liberal dos mecanismos verticais de controle estatal, a ideia anisiana de educação comunitária tem como núcleo um ser humano regional, enraizado em uma terra limitada, socializado no interior de um complexo cultural particular, capaz de condensar, por

\footnotetext{
25 SANTOS, Heloisa Occhiuze dos. Ideário pedagógico municipalista de Anísio Teixeira. Cadernos de Pesquisa, no 110, p. 105-124, 2000.

${ }^{26}$ TEIXEIRA. Educação não é privilégio, cit., p. 63.

${ }^{27}$ Ibidem, p. 69.

${ }^{28}$ VIANA, Oliveira. Instituições Políticas Brasileiras. Brasília, Edições do Senado Federal. 2019.
} 
meio da escola, o caráter da coletividade. A própria distribuição de sistemas escolares em país de dimensões continentais não se pode operar sem recurso à organização de forças regionais capazes de concorrer pela expansão qualificada da educação básica. Segundo o autor:

\begin{abstract}
Não pensamos, pois, reformar a escola brasileira com a imposição de modelos $a$ priori formulados por um centro ou por alguns poucos centros dirigentes, mas antes liberar as forças locais de iniciativa e responsabilidade e confiar-lhes a tarefa de construir a escola nacional, sob os auspícios de uma inteligente assistência técnica dos estados e da União. Não somos nação a ser moldada napoleonicamente do centro para a periferia, mas um grande e variado império a ser assistido e, quando muito, coordenado pelo centro, a fim de poder prosseguir no seu destino de criar nos trópicos uma grande cultura, diversificada nas suas características regionais e una nos seus propósitos e aspirações de civilização e democracia. ${ }^{29}$
\end{abstract}

A valorização dos recursos humanos locais se estende à formação qualificada e regionalizada de professores. As escolas do magistério, instaladas no município e para o município, devem ser supervisionadas pelo governo estadual, a quem cabe estabelecer uma política de formação docente. Anísio Teixeira, porém, não interdita a municípios mais desenvolvidos a possibilidade de desenvolver escolas superiores exemplares que ofereçam pessoal qualificado às cidades vizinhas ${ }^{30}$. À frente da educação no Distrito Federal, o próprio autor dá-nos prova de como é pertinente estabelecer escolas de vanguarda capazes de irradiar seus métodos e seus profissionais para escolas empobrecidas de recursos humanos e materiais. Funda-se, por isso, a Escola de Educação do Rio de Janeiro, no âmbito do Instituto de Educação, instituição de ensino superior, secundário e primário, voltada para a integração dinâmica entre os novos profissionais da Educação e as crianças e adolescentes da escola básica. Em 1935, quando funda a Universidade do Distrito Federal ${ }^{31}$, Anísio estabelece o curso superior de magistério como um dos primeiros a compor a universidade, que mais tarde seria dissolvida por Getúlio Vargas.

Esse movimento de profissionalização docente se chocou com a prática corrente de se entregar o cargo de professor primário a qualquer pessoa alfabetizada capaz de ensinar grosseiramente o beabá - prática comum nos rincões sertanejos e mesmo em cidades mais próximas das capitais. Profissionalizar a escola equivale a prover pessoal suficientemente qualificado para conduzir, com autonomia e segurança, os destinos próprios de cada unidade

\footnotetext{
${ }^{29}$ TEIXEIRA. Educação não é privilégio, cit., p. 66.

${ }^{30}$ PAULILO. As estratégias de administração das políticas públicas de educação na cidade do Rio de Janeiro entre 1922 e 1935 , cit.

${ }^{31}$ XAVIER, Libânia Nacif. Universidade, pesquisa e educação pública em Anísio Teixeira. História, Ciências, Saúde-Manguinhos, v. 19, nº 2, p. 177-191, 2012.
} 
escolar $^{32}$. Anísio viveu momento histórico em que apenas se iniciava a formação superior de profissionais da educação, de modo que, em seu tempo, burocratas ineptos se foram gradualmente substituindo por educadores de formação. Por meio de arrojado sistema de formação docente, potencialmente integrado em escala nacional, tornar-se-ia possível estimular a transformação estrutural da educação básica.

A crescente ocupação de cargos educacionais por educadores representou o predomínio das forças sociais sobre as forças políticas. Protegida da influência sectária de partidos, orientada para realizar satisfatoriamente seus propósitos pedagógicos, a administração educacional deve se desempenhar não por emissários da burocracia estatal, mas por educadores livres da interferência corruptora dos governantes de ocasião. "Para isso, os estados democráticos organizam os serviços educativos de modo a que se governem a si mesmos, obedecendo, tão-somente, às próprias influências ou às que se façam sentir na sociedade a que se destinam". ${ }^{33}$

Não surpreende que tenha Anísio colaborado, entre as décadas de 50 e 70, na estruturação de entidades geridas por profissionais da Educação. São bons exemplos o Instituto Nacional de Estudos e Pesquisas Educacionais (hoje INEP - Anísio Teixeira), a Coordenação de Aperfeiçoamento de Pessoal de Ensino Superior (CAPES), além do Conselho Federal de Educação (hoje Conselho Nacional de Educação). Tais instituições se enquadram num amplo feixe de organizações públicas constituídas por profissionais de educação, técnicos e gestores públicos, que, unidas, compõem o quadro amplo das instituições consultivas e deliberativas da educação no Brasil. Nota-se, no envolvimento pessoal de Anísio Teixeira na construção de tais instituições, o ímpeto imaginativo e propositivo que caracteriza os intelectuais construtivistas institucionais.

Quando foi nomeado secretário de Educação na Bahia, entre 1947 e 1951, engenhou o que viria a ser o bem-sucedido experimento do Centro Educacional Carneiro Ribeiro, popularizado como Escola Parque. O Centro foi projetado para submeter ao teste da realidade as ideias audaciosas de Anísio, no que se refere à combinação dinâmica de vários conhecimentos e técnicas. "O Centro Popular de Educação Carneiro Ribeiro foi criado como um modelo para a universalização da educação integral do homem comum" ${ }^{34}$, e uma

\footnotetext{
32 BARBOSA, Nayara Ferreira de Moura; JARDILINO, José Rubens de Lima. A formação de professores: notas sobre o pensamento educacional de Anísio Teixeira. Educação em Perspectiva, Viçosa, v. 3, nº 2, p. 320339, 2012.

${ }^{33}$ TEIXEIRA. Educação não é privilégio, cit., p. 57.

${ }^{34}$ CORDEIRO, Célia Maria Ferreira. Anísio Teixeira, uma "visão" do futuro. Estudos Avançados, v. 15, n 42, p. 241-258, 2001.
} 
educação assim destinada ao homem comum se deveria efetivar por meio de arranjos plurais e no entanto ordenados. Contra a prática corrente de aligeiramento, Anísio propõe um modelo integral em dois sentidos: no tempo, cobrindo turnos matutinos e vespertinos, e na concepção pedagógica, visando desenvolver o aluno em sua inteireza humana.

\begin{abstract}
O complexo educacional idealizado por Anísio Teixeira constava de quatro escolas-classe com capacidade para mil alunos cada, em dois turnos de quinhentos alunos, e uma escola-parque composta dos seguintes setores: (a) pavilhão de trabalho; (b) setor socializante; (c) pavilhão de educação física, jogos e recreação; (d) biblioteca; (e) setor administrativo e almoxarifado; (f) teatro de arena ao ar livre e $(\mathrm{g})$ setor artístico. A escola-parque complementava de forma alternada o horário das escolas-classe, e assim o aluno passava o dia inteiro no complexo, onde também se alimentava e tomava banho. ${ }^{35}$
\end{abstract}

O projeto educacional anisiano intentou responder à necessidade de acomodar a escola na locomotiva industrial da modernidade, o que envolveu ampla reestruturação institucional e reorientação das práticas pedagógicas no sentido de habilitar o aluno ao exercício de sua cidadania. No pensamento de Anísio Teixeira, a educação só é eficazmente transformada na medida em que se pode delimitar os domínios escolares e identificar objetivos estratégicos ao alcance das instituições educativas. Nota-se em suas ideias e projetos um traço distintivo do construtivismo institucional, qual seja, a noção central de que as metas colocadas no horizonte de expectativas só se podem atingir por meio da intervenção criativa e inteligente na ordem presente. O prognóstico só é possível mediante acurado e minucioso diagnóstico das instituições vigentes, de modo a imaginar o possível a partir do real. Segundo Hermes Lima $^{36}$, Anísio Teixeira confiava na "capacidade inerente à inteligência de divisar o futuro, de perceber o que está nascendo. Nessa função, o papel revolucionário da inteligência, verdadeiro agente de mudança, se exerce desmontando as peças do estabelecido.” A educação é concebida como artefato sujeito à ação criadora, e não como mero subproduto das relações de produção ou como inerte joguete das facções político-partidárias.

\title{
60 construtivismo institucional em Anísio Teixeira
}

Ao longo de sua carreira como publicista e administrador público da educação, Anísio se empenhou em oferecer alternativas institucionais à educação que, em sua época, achava-se desorientada, desaparelhada e desarticulada com outras esferas da vida social.

\footnotetext{
${ }^{35}$ CAVALIERE, Ana Maria. Anísio Teixeira e a educação integral. Paidéia, Ribeirão Preto, v. 20, n 46, p. 256, 2010.

${ }^{36}$ LIMA. Anísio Teixeira, cit., p. 147.
} 
Suas explicações e propostas podem ser classificados como legatárias do construtivismo institucional, corrente intelectual do pensamento social brasileiro marcada por um duplo movimento de redimensionamento da relação estrutura-agente, e construção ou reforma de instituições capazes de promover transformações no interior da sociedade.

O construtivismo institucional é caracterizado por uma compreensão dinâmica da relação estabelecida entre estruturas sociais e agentes políticos, relação em que estes podem interferir na recomposição gradual dos elementos estruturais da vida em sociedade - a imaginação institucional a serviço da transformação progressiva. Essa intervenção é usualmente fundada na inteligência criativa de agentes capazes de operacionalizar mudanças estruturais. A obra de Anísio Teixeira, no que se refere à sua concepção de educação pública e de ação do estado, pressupõe que as estruturas sociais não se encontram entrelaçadas a uma meta-estrutura indivisível e inatingível por meios convencionais de ação política. Trata-se, ao contrário, de uma concepção político-pedagógica em que as bases civilizatórias do país podem ser fortalecidas por meio da implementação de modelo educacional adaptado às necessidades particulares da sociedade brasileira.

Diante do diagnóstico desalentador do Brasil como um país dilacerado por fortes antagonismos sociais e econômicos, Anísio compreende que a escola, como instituição, pode não somente refletir as desigualdades como aprofundar a distância entre os que se podem educar e os que não possuem as credenciais de classe necessárias para obtenção do acesso à escola de qualidade. Esse diagnóstico, contudo, não traz consigo um juízo definitivo a respeito das estruturas sociais que sustentam a ordem presente. Ao contrário, o pensamento anisiano é pródigo em proposições de superação dessa ordem social discriminatória, ordem em que não pode frutificar nenhuma semente de progresso social e econômico. No pensamento de Anísio Teixeira, recursos humanos e materiais se complementam na efetivação de projetos transformadores, e é por esse motivo que em sua obra institucional e teórica se verifica a profissionalização sistemática de quadros, por um lado, a reordenação inventiva da administração pública educacional, por outro lado. $\mathrm{O}$ agente e a estrutura são, portanto, compreendidos de modo a ressaltar o caráter artificial e relativamente maleável das instituições humanas na ordem presente.

Também caracteriza o construtivismo institucional a ênfase analítica no processo amplo de fundação de bases nacionais para a edificação do desenvolvimento do Brasil, o que se traduz num esforço de formulações teóricas cujo objetivo é encontrar soluções específicas para problemas brasileiros. Trata-se de identificar, explicar e propor meios factíveis de 
superação dos obstáculos situados no caminho nacional para a prosperidade e o progresso. Nesse sentido, não deve o intelectual se fiar em ideários e programas bem-sucedidos em outros países, cedendo ao colonialismo mental. Deve-se buscar uma interpretação original da situação brasileira, o que, se não implica rejeição irrefletida a modelos estrangeiros, implica, isto sim, em encontrar e aproveitar possibilidades nativas de transformação - o que pode exigir convênios com nações desenvolvidas de quem possamos assimilar o ferramental técnico e científico. Ao tratar do problema da escassez de profissionais qualificados na ciência e na tecnologia, Anísio afirma ser necessário estabelecer programas de intercâmbio com países dispostos a fornecer pessoal para orientar técnicos brasileiros. ${ }^{37}$

Verifica-se no pensamento anisiano uma preocupação recorrente quanto à formação e à consolidação da unidade nacional. Era preciso estender as redes escolares dos rincões sertanejos às periferias suburbanas, pois uma sociedade analfabeta, inepta e ainda obscurecida pela ignorância não poderá jamais alcançar o senso nacional de união e coesão desejável. Para corrigir o quadro desalentador de analfabetismo e ausência de escolas, seriam necessárias mudanças tão abrangentes e organizadas que apenas o Estado, como instituição catalisadora de recursos humanos e materiais, poderia empreender. Só o Estado, na concepção anisiana, seria capaz de reconduzir a educação no sentido da transformação estrutural. Anísio está situado, nesse sentido, num cenário histórico de crescente apelo à intervenção estatal na resolução de problemas nacionais:

\begin{abstract}
Desde a segunda metade do século XIX, os países mais desenvolvidos vinham cuidando da implantação definitiva da escola pública, universal e gratuita. De fato, esse século se caracterizou, quanto à educação, pela acentuada tendência do Estado de agir como educador. É que as exigências da sociedade industrial impunham modificações profundas na forma de se encarar a educação e, em consequência, na atuação do Estado, como responsável pela educação do povo. (...) $\mathrm{O}$ capitalismo, notadamente o capitalismo industrial, engendra a necessidade de fornecer conhecimentos a camadas cada vez mais numerosas, seja pelas exigências da própria educação, seja pelas necessidades do consumo que essa produção acarreta. $^{38}$
\end{abstract}

Anísio compreende que somente uma escola pluritécnica e multifacetada, distribuída em todo o território nacional e organizada a partir de diretrizes estabelecidas acima das particularidades regionais, poderia engendrar uma sociedade tecnicamente qualificada e unificada. "A educação é um fenômeno de civilização", como outras coisas que "nascem de condições sociais determinadas, e ao homem mais não é dado que redirigi-

\footnotetext{
37 TEIXEIRA. Educação para a Democracia, cit.

${ }^{38}$ ROMANELLI. História da Educação no Brasil, cit., p. 59.
} 
las"39. Suscetível de ser redirigida, a educação está ligada ao estado evolutivo da civilização. Caberia à escola veicular uma ação intencional dos homens, ação sujeita à influência estorvante de fatores extra-escolares, porém não determinados por eles. Anísio indica, assim, o papel da educação escolar na edificação de um país independente e desenvolvido, salientando, embora, ser este papel apenas um componente do conjunto de fatores conducentes a um estado mais elevado de realização material do país. Note-se que as expectativas sobre a potencialidade transformadora da escola são moderadas por um aguçado senso de realismo político-administrativo.

A obra anisiana, tanto em seus aspectos teóricos e práticos, o situa em posição privilegiada entre os intelectuais que compõem a galeria do pensamento brasileiro. Do ponto de vista teórico, suas ideias e propostas se caracterizam pela formulação de saídas estratégicas para as variadas encruzilhadas históricas, sociais, políticas e econômicas do país. A provisão de soluções específicas para problemas especificamente brasileiros está fundada na concepção construtivista das instituições humanas, marcada pela rejeição a determinismos de ordem cultural ou estrutural, e por um compromisso inatacável com a promoção do desenvolvimento nacional mediante reforma progressiva das instituições. Um traço do pensamento anisiano, como em outros intelectuais de cariz construtivista institucional, é a recusa à capitulação diante de estruturas de dominação e espoliação da sociedade brasileira - o que o predispõe ao experimentalismo.

As experiências anisianas na administração educacional do Distrito Federal e do Estado da Bahia produziram dois modelos de experimentalismo pedagógico, pois tanto as escolas experimentais da capital fluminense quanto as escolas-parque da periferia baiana foram construídas com o objetivo de servirem de laboratório educacional, adotando organização escolar e práticas pedagógicas inovadoras ${ }^{40}{ }^{41}$. Tal experimentalismo pedagógico somente se pode adotar mediante a admissão das instituições políticas como instrumentos úteis na recomposição inteligente e criativa de estruturas sociais, políticas e econômicas. Ao estimular a organização educacional em formatos operacionais adaptados às necessidades particulares da comunidade escolar, Anísio Teixeira produziu modelos experimentais replicados, em seguida, em diferentes regiões e sob diversas condições

\footnotetext{
39 TEIXEIRA. Educação para a Democracia, cit., p. 40.

${ }^{40}$ CAVALIERE. Anísio Teixeira e a educação integral, cit.

41 XAVIER, Libânia Nacif; PINHEIRO, José Gledison Rocha. Da LAB School de Chicago às escolas experimentais do Rio de Janeiro dos anos 1930, História da Educação, v. 20, nº 50, p. 177-191, 2016.
} 
políticas - como os CIEP's no Rio de Janeiro, para citar apenas um exemplo da reverberação do experimentalismo anisiano ${ }^{42}$.

\section{Conclusões}

Neste breve texto pretendemos demonstrar algumas qualidades explicativas e propositivas da obra de um dos mais eminentes intelectuais da Educação no Brasil. Se o futuro do país é influenciado por análises e proposições de pensadores e publicistas, é do interesse público refletir a respeito dos ícones selecionados como representantes das aspirações coletivas e como modelos exemplares para a formulação e implementação de políticas públicas. No caso da Educação, é necessário retomar-se a figura de Anísio Teixeira como fonte de ideias e projetos institucionais capazes de influir positivamente na reestruturação da vida social.

Deve-se buscar alternativas teóricas com potencial de informar planos de ação transformadora da realidade educacional. O pedagogo de Caetité apontou o caminho por que poderia seguir o Brasil, em direção à modernização técnico-científica e ao desenvolvimento integral das potencialidades do indivíduo e da sociedade. Às portas da revolução industrial, Anísio Teixeira compreendeu ser o momento histórico auspicioso para iniciativas de reorganização institucional visando atingir os objetivos de mudanças estruturais colocados no horizonte de expectativas da nação. À época, a ciência e a técnica poderiam servir de ferramentas úteis na edificação de civilização democrática e pujante.

O paradigma anisiano de educação técnico-científica não se esgotou na preparação de força de trabalho qualificada para a recém-chegada indústria nacional, mas, na verdade, permanece válido para orientar políticas educacionais de capacitação de adolescentes e jovens, sobretudo em tempos de aceleradas transformações tecnológicas, de mudanças vertiginosas no contato travado entre as juventudes em idade escolar e as oportunidades de aproveitamento do potencial científico e técnico propiciado pela modernidade. Para compatibilizar a educação escolar e as demandas contemporâneas por formação consistente para as classes emergentes, faz-se necessário reconduzir a política educacional ao patamar de integração estratégica entre os corredores escolares e as bases produtivas do país, de modo a valorizar a inteligência criativa do estudante brasileiro e capacitá-lo para se desenvolver, em primeira pessoa, e promover o desenvolvimento à sua volta, em terceira pessoa.

\footnotetext{
${ }^{42}$ CORDEIRO. Anísio Teixeira, uma "visão" do futuro, cit.
} 
Para um país desejoso de ascender à posição de nação desenvolvida, uma educação escolar estagnada equivale a intolerável desperdício de recursos humanos e materiais. Diante de correntes intelectuais que apregoam aos quatro ventos a ineficiência sistêmica da escola em acelerar o processo de democratização socioeconômica, reafirme-se a função dinamizadora desempenhada pelo ensino sobre a vida econômica e sociocultural do Brasil. No interior de uma nova estratégia nacional de desenvolvimento, só uma educação escolar moderna e modernizante pode assentar os alicerces da civilização que almejamos construir nos trópicos: criativa, enérgica e cheia de vitalidade. Sobre as mudanças na estrutura de classes e o papel estratégico do poder público na reorganização produtiva do país, escreve Mangabeira Unger, "a revolução brasileira estava em o Estado ajudar a construir minoria trabalhadora organizada, sediada na indústria, para mudar o Brasil."43 Agora, neste século XXI de economia do conhecimento e indústria 4.0, o papel revolucionário do Estado "está em liderar as inovações institucionais que permitiriam a maioria seguir o exemplo da vanguarda de emergentes" ${ }^{4}$. A capacitação técnico-científica das próximas gerações de trabalhadores qualificados dar-se-á principalmente por meio de educação de alcance extensivo e de elevadas expectativas.

É notável que um programa educacional orientado nesse sentido transformador tenha sido elaborado pelo próprio Roberto Mangabeira Unger, sob inspiração de Anísio Teixeira. À frente da Secretaria de Assuntos Estratégicos, em 2015, o então ministro Unger desenvolveu programa Pátria Educadora: a qualificação do ensino básico como obra de construção nacional. Nota-se na proposta traço tipicamente anisiano no sentido de estabelecer, em meio à diversidade regional e às assimetrias de capacidade de investimento e aproveitamento de recursos públicos por prefeitos e governadores, um senso superior de unidade institucional fundada em metas estratégicas de desenvolvimento educacional assumidas de modo coletivo e vinculante. A proposta, ao ser publicizada, suscitou resistências por parte de personalidades e entidades profissionais que a rejeitaram, acusandona de meritocrática.

A educação brasileira, sobretudo em seu nível básico, enfrenta ainda deficiências da maior gravidade. Diferentemente de áreas como a saúde ou a segurança pública, os resultados práticos das políticas educacionais só se revelam ao fim de uma geração, o que

\footnotetext{
${ }^{43}$ UNGER, Roberto Mangabeira Unger. Depois do colonialismo mental: repensar e reorganizar o Brasil. Autonomia Literária. São Paulo, 2018, p. 16.

${ }^{44}$ Ibidem.
} 
contribui para a redução das iniciativas de inovação institucional - que exigem projeto estratégico de ação e avaliação integrados. Por esse motivo, a atuação de governantes e administradores públicos, na ausência de arrojados projetos de Estado capazes de definir meios e fins para a consecução dos objetivos de qualificação do ensino, tenderá a buscar inspiração no reservatório de ideias pedagógicas, abastecido por intelectuais, pesquisadores, professores e publicistas de variada estatura intelectual. Eis por que defendemos a necessidade de reorientação teórica da busca por soluções inteligentes para nossos numerosos e complexos problemas educacionais. Não é razoável supor que seremos capazes de encarar os desafios impostos pela realidade por meio de elucubrações e devaneios que pouco explicam e tampouco inspiram. 


\section{Referências Bibliográficas}

ARAÚJO, Gilda Cardoso de. A relação entre federalismo e municipalização: desafios para a construção do sistema nacional e articulado de educação no Brasil. Educação $e$ Pesquisa, v. 36, n. 1, p. 389-402. 2010. Disponível em: https://doi.org/10.1590/S151797022010000100013. Acessado 25 junho 2021.

BALESTRIN, Mariana; SPONCHIADO, Breno Antônio; SUDBRACK, Edite Maria. A contribuição do pensamento de Anísio Teixeira para a formação do cidadão democrático na sociedade brasileira. Revista de Educação Popular, v. 16, n. 2, p. 125 135, 21 nov. 2017.2 Disponível em http://www.seer.ufu.br/index.php/reveducpop/article/view/40525. Acessado 28 junho 2021.

BARBOSA, Nayara Ferreira de Moura; JARDILINO, José Rubens de Lima. A formação de professores: notas sobre o pensamento educacional de Anísio Teixeira. Educação em Perspectiva, Viçosa, v. 3, n. 2, p. 320-339, 2012. Disponível em https://www.repositorio.ufop.br/bitstream/123456789/4893/1/ARTIGO_Forma\%C3 \%A7\%C3\%A3oProfessoresNotas.pdf. Acessado 21 junho 2021.

CAMPOS, Francisco. O Estado Nacional: sua estrutura, seu conteúdo ideológico. Brasília, Senado Federal, Conselho Editorial. 2001. 226 p.

CAVALIERE, Ana Maria. Anísio Teixeira e a educação integral. Paidéia, Ribeirão Preto, v. 20, n. 46, p. 249-259, 2010. Disponível em: https://doi.org/10.1590/S0103863X2010000200012. Acessado 19 junho 2021.

CORDEIRO, Célia Maria Ferreira. Anísio Teixeira, uma "visão" do futuro. Estudos Avançados, v. 15, n. 42, p. 241-258, 2001. Disponível em: https://doi.org/10.1590/S0103-40142001000200012. Acessado 19 junho 2021.

DALLABRIDA, Norberto. A reforma Francisco Campos e a modernização nacionalizada do ensino secundário. Educação, Porto Alegre, v. 32, n. 2, p. 185-191, 2009. Disponível

em https://revistaseletronicas.pucrs.br/ojs/index.php/faced/article/view/5520. Acessado 21 junho 2021.

LIMA, Hermes. Anísio Teixeira: estadista da Educação. Rio de Janeiro, Civilização Brasileira. 1978. $212 \mathrm{p}$.

MENDONÇA, Ana Waleska et al. Pragmatismo e desenvolvimentismo no pensamento educacional brasileiro dos anos de 1950/1960. Revista Brasileira de Educação, v. 11, n. 31, p. 96-113, 2006. Disponível em: https://doi.org/10.1590/S141324782006000100008 . Acessado 20 junho 2021.

PAULILLO, André Luiz. As estratégias de administração das políticas públicas de educação na cidade do Rio de Janeiro entre 1922 e 1935. Revista Brasileira de Educação, v. 14, n. 42, p. 440-455, 2009. Disponível em: https://doi.org/10.1590/S141324782009000300004 . Acessado 24 junho 2021.

ROMANELLI, Otaíza. História da Educação no Brasil. 8a edição. Petrópolis, Vozes. 1986. $269 \mathrm{p}$.

SANTOS, Heloisa Occhiuze dos. Ideário pedagógico municipalista de Anísio Teixeira. Cadernos de Pesquisa, n. 110, p. 105-124, 2000. Disponível em: https://doi.org/10.1590/S0100-15742000000200004. Acessado 24 junho 2021

TEIXEIRA, Anísio. Educação é um direito. São Paulo, Companhia Editora Nacional. 1968. $165 \mathrm{p}$.

TEIXEIRA, Anísio. Educação não é privilégio. $5^{\mathrm{a}}$ edição. Rio de Janeiro, Editora UFRJ. 1994. $252 \mathrm{p}$. 
TEIXEIRA, Anísio. Educação para a Democracia. $2^{\mathrm{a}}$ edição. Rio de Janeiro, Editora UFRJ. 1997. $266 \mathrm{p}$.

TEIXEIRA, Anísio. Pequena introdução à Filosofia da Educação: a escola progressiva ou a transformação da escola. $6^{a}$ edição. São Paulo, Companhia Editora Nacional. 1971. $150 \mathrm{p}$.

TEIXEIRA, Carlos Sávio Gomes. Modos de explicar o Brasil: o estruturalismo sociológico de Florestan Fernandes e o construtivismo institucional de Roberto Mangabeira Unger. Sinais Sociais, Rio de Janeiro, v. 10 n. 28, p. 55-79, mai.-ago. 2015. Disponível em: http://dcp.uff.br/wp-content/uploads/sites/327/2020/10/modos-de-explicar-obrasil.pdf. Acessado em 11 agosto 2021.

TEIXEIRA, Carlos Sávio Gomes; MEDEIROS, Tiago. O construtivismo institucional e a democracia brasileira. Revista de Ciências do Estado, Belo Horizonte, vol. 6, n. 2, p. $01-20$ 2021.

Disponível em: https://periodicos.ufmg.br/index.php/revice/article/view/e35659/e35659. Acessado 17 setembro 2021.

UNGER, Roberto Mangabeira Unger. Depois do colonialismo mental: repensar e reorganizar o Brasil. São Paulo, 2018. Autonomia Literária. 308 p.

VIANA, Oliveira. Instituições Políticas Brasileiras. Brasília, Edições do Senado Federal. 2019. $582 \mathrm{p}$

XAVIER, Libânia Nacif. Universidade, pesquisa e educação pública em Anísio Teixeira. História, Ciências, Saúde-Manguinhos, v. 19, n. 2, p. 669-682, 2012. Disponível em: https://doi.org/10.1590/S0104-59702012000200017. Acessado 26 junho 2021.

XAVIER, Libânia Nacif; PINHEIRO, José Gledison Rocha. Da LAB School de Chicago às escolas experimentais do Rio de Janeiro dos anos 1930, História da Educação, v. 20, n. 50, p. 177-191, 2016. Disponível em: https://doi.org/10.1590/2236-3459/62397. Acessado 21 junho 2021. 
Como citar este artigo: ROCHA, Rafael Valladão. Estado e Educação no construtivismo institucional de Anísio Teixeira. Revista de Ciências do Estado, Belo Horizonte, v. 6, n. 2, p. 1-27, 2021.

Recebido em 05.09.2021

Publicado em 17.12.2021 